\title{
Toxoplasmose ağuda: estudo da frequiência, taxa de transmissão vertical e relação entre os testes diaģnósticos materno-fetais em gestantes em estado da Regiãa Centro-Oeste do Brasil
}

\author{
Acute toxoplasmosis: study of the frequency, vertical tansmission rate and the relationship
} between maternal-fetal diagnostic tests during pregnancy in a Central-Western state of Brazil

Ernesto Antonio Figueiró-Filho' ${ }^{1}$ Alessandro Henrique Antunes Lopes ${ }^{2}$, Flávio Renato de Almeida Senefonte ${ }^{2}$, Virgilio Gonçalves de Souza Júnior ${ }^{3}$, Carlos Augusto Botelho ${ }^{3}$, Mauro Silvério Figueiredo ${ }^{4}$, Geraldo Duarte ${ }^{5}$

\section{RESUMO}

Objetivos: estabelecer a freqüência da toxoplasmose aguda em gestantes, a taxa de transmissão vertical e o resultado perinatal dos fetos infectados. Objetivou-se, ainda, avaliar a relação entre os principais testes materno-fetais de diagnóstico da toxoplasmose durante a gestação, bem como a relação entre faixa etária e a infecção aguda pelo Toxoplasma gondii. Métodos: estudo prospectivo longitudinal com 32.512 gestantes submetidas à triagem pré-natal pelo Programa de Proteção à Gestante de Mato Grosso do Sul, no período de novembro de 2002 a outubro de 2003. Utilizaram-se método ELISA (IgG e IgM) e teste de avidez de anticorpos IgG para diagnóstico da toxoplasmose materna, e PCR no líquido amniótico, para diagnóstico da infecção fetal. A avaliação das variáveis foi feita pelas médias, ao passo que a correlação entre algumas variáveis foi avaliada pelo teste do $\chi^{2}$ e teste de Fisher bicaudado em tabelas de contingência de dupla entrada. Resultados: encontrou-se freqüência de 0,42\% para a infecção aguda pelo T. gondii na população de gestantes, sendo $92 \%$ delas expostas previamente à infecção e $8 \%$ suscetíveis. Nas gestantes com sorologia IgM reagente, a faixa etária variou de 14 a 39 anos, com média de 23 $\pm 5,9$ anos. Não houve relação significativa estatisticamente entre faixa etária e infecção materna aguda pelo T. gondii (p=0,73). Verificou-se taxa de transmissão vertical de 3,9\%. Houve relação estatisticamente significativa ( $\mathrm{p}=0,001)$ entre o teste de avidez (IgG) baixo $(<30 \%)$ e presença de infecção fetal, e ausência de toxoplasmose fetal quando a avidez apresentava-se elevada (>60\%). Houve associação significativa estatisticamente ( $(\mathrm{=}=0,001)$ entre infecção fetal (PCR em líquido amniótico) e infecção neonatal. Conclusões: a freqüência da toxoplasmose aguda materna apresentou-se abaixo do observado em outras investigações no Brasil. Entretanto a taxa de transmissão vertical não foi discordante do encontrado em outros estudos. O teste de avidez dos anticorpos IgG, quando associado à idade gestacional e data de realização do exame, mostrou-se útil para orientar a terapêutica e avaliar o risco de transmissão vertical, permitindo afastá-lo quando havia avidez elevada previamente a 12 semanas. O PCR positivo foi associado à pior prognóstico neonatal, demonstrando-se método específico para diagnóstico intra-útero da infecção fetal.

PALAVRAS-CHAVE: Toxoplasmose/epidemiologia; Toxoplasmose congênita; Complicações infecciosas na gravidez; Infecção; Gravidez

\section{ABSTRACT}

Purpose: to establish the frequency of acute toxoplasmosis in pregnant women, vertical transmission rate and the perinatal results of the infected fetuses and also to evaluate the relationship between the most used maternal-fetal diagnostic tests for toxoplasmosis during pregnancy and the relationship between age and acute toxoplasmosis infection during pregnancy.

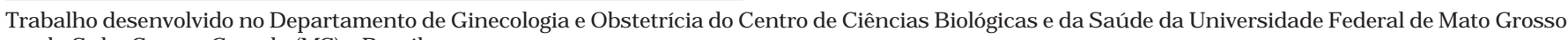
do Sul - Campo Grande (MS) - Brasil.

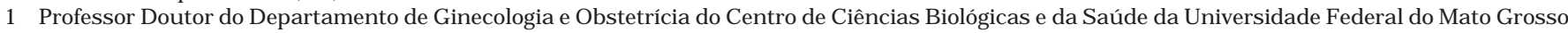
do Sul - Fundação Universidade Federal do Mato Grosso do Sul - FUFMS - Campo Grande (MS), Brasil.

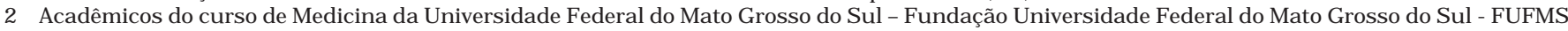
- Campo Grande (MS), Brasil.

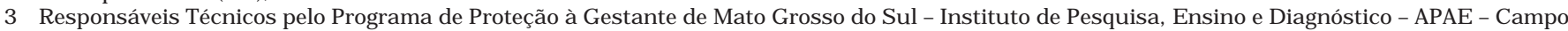
Grande (MS), Brasil

4 Setor de Métodos Moleculares do Laboratório Medicina Diagnóstica - São Paulo (SP), Brasil.

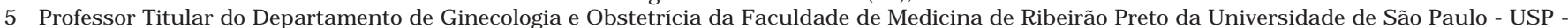
Ribeirão Preto (SP), Brasil.

Correspondência: Ernesto Antonio Figueiró-Filho

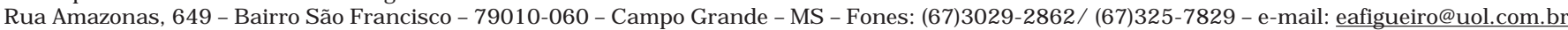


Methods: longitudinal prospective study of 32,512 pregnant women attended by The Pregnancy Protection Program of the State of Mato Grosso do Sul - Brazil, from November 2002 to October 2003. ELISA (IgG and IgM) and IgG avidity test were performed for maternal diagnosis and amniotic fluid PCR for fetal investigation of the infection. The relationship between data was analyzed statistically by the $\chi^{2}$ or two-sided Fisher's exact test in contingency tables. Results: a $0.42 \%$ frequency of acute Toxoplasma gondii infection among pregnant population was found, where $92 \%$ were previously exposed and $8 \%$ were susceptible. Among IgM-positive pregnant women, the age ranged from 14 to 39 years, with a mean of $23 \pm 5.9$ years. There was no statistically significant relationship between age and maternal acute $T$. gondii infection $(\mathrm{p}=0.73)$. The vertical transmission rate was $3.9 \%$. A statistically significant relationship was shown $(\mathrm{p}=0.001)$ between a lower avidity IgG test $(<30 \%)$ and the presence of fetal infection and a higher IgG avidity test $(>60 \%)$ and the absence of fetal infection. There was a statistically significant association $(\mathrm{p}=0.001)$ between fetal infection (amniotic fluid PCR) and neonatal infection. Conclusions: maternal acute toxoplasmosis frequency was lower than the Brazilian national parameters, whereas vertical transmission rate did not differ from the rates found in other studies. The IgG avidity test, when associated with gestational age and the examination date, was useful to evaluate the therapeutical options and to consider the risk of vertical transmission when performed before 12 weeks. Positive PCR in amniotic fluid showed a positive relationship with the worst neonatal prognosis, being a specific method in diagnosing intrauterine fetal infection.

KEYWORDS: Toxoplasmosis/epidemiology; Toxoplasmosis, congenital; Pregnancy complications, infectious; Infection; Pregnancy

\section{Introdução}

A toxoplasmose é zoonose cujo agente etiológico é o Toxoplasma gondii, sendo identificados em seu ciclo de vida complexo dois hospedeiros: o gato, como hospedeiro definitivo, e o homem, mamíferos e aves, como hospedeiros intermediários $^{1}$. Diversas são as formas de transmissão, ocorrendo por ingestão de oocistos encontrados na terra, areia e nos alimentos, de cistos teciduais encontrados nas carnes cruas e mal cozidas de porco, carneiro e bovina, e por via transplacentária. Mais raramente ocorre a transmissão por meio de transfusão sanguínea, transplante de órgãos e acidente em laboratório ${ }^{1,2}$.

A infecção toxoplásmica ocorre em todo o mundo, sendo que de 70 a 100\% dos adultos são considerados infectados ${ }^{2}$. No Brasil, a prevalência de anticorpos IgG na população geral varia de 54\% no Centro-Oeste a $75 \%$ no Norte $^{2}$. A infecção em humanos imunocompetentes é assintomática em 80 a $90 \%$ dos $\operatorname{casos}^{1}$, sendo a doença uma exceção no homem ${ }^{2}$. Quando sintomática, é autolimitada e apresenta-se como quadro febril, linfoadenopatia, hepatoesplenomegalia e eventual rash cutâneo ${ }^{1}$. Em pacientes imunocomprometidos podem ocorrer encefalite, coriorretinite, pneumonite e miocardite ${ }^{3}$.

A toxoplasmose adquirida durante a gestação, por constituir uma das formas de transmissão do parasita, apresenta especial relevância pelos danos causados ao desenvolvimento do feto. Em geral, o risco de adquirir toxoplasmose durante o período gestacional correlaciona-se a três fatores: a prevalência na comunidade, o número de contatos com uma fonte de infecção e o número de mulheres suscetiveis (não imunizadas por infecção prévia) na comunidade ${ }^{1}$. No Brasil, existem estudos sobre prevalência de gestantes soropositivas para IgG anti-Toxoplasma gondii em alguns estados, como Rio de Janeiro $(77,1 \%)^{4}$, Pernambuco $(69,4 \%)^{5}$, Rio Grande do Sul $(74,5 \%)^{6}$, Bahia $(64,9 \%)^{7}$ e Paraná $(67 \%)^{8}$.

Durante a gestação, o risco de transmissão vertical (TV) está praticamente restrito às primoinfecções ${ }^{1}$, sendo observado que mulheres que já apresentavam soropositividade antes da gravidez geralmente não infectam seus fetos ${ }^{9}$. O parasita atinge o concepto por via transplacentária causando danos de diferentes graus de gravidade, dependendo da virulência da cepa do parasita, da capacidade da resposta imune da mãe e do período gestacional em que a mulher se encontra. Quando a infecção materna ocorre no primeiro trimestre da gestação, a ocorrência de TV é menor que no terceiro trimestre, contudo a gravidade da doença no neonato é maior ${ }^{9}$.

A taxa de transmissão ao feto durante a primoinfecção é de 25,54 e $65 \%$ no primeiro, segundo e terceiro trimestres, respectivamente ${ }^{10}$. Nas pacientes imunocomprometidas pode haver reativação da infecção crônica, havendo risco de transmissão ao feto em qualquer período gestacional $^{1,3}$. Encontraram-se, ainda, relatos de casos de infecção congênita em crianças nascidas de mulheres que se infectaram com $T$. gondii antes da concepção, apresentando imunodeficiência ou sistema imune normal. Apesar de serem relatos isolados, constituem um fator a ser analisado quando são avaliados os resultados dos testes sorológicos ${ }^{11}$.

O diagnóstico da infecção materna é feito pelo perfil sorológico da doença aguda, que exibe positividade tanto para anticorpos IgM como para 
IgG. Como os niveis de anticorpos IgM podem manter-se positivos por até 18 meses após a infecção ${ }^{1}$, outros métodos devem ser utilizados para diferenciação de infecção aguda ou crônica, como o teste de avidez de anticorpos IgG, demonstrando baixa avidez $(<30 \%)$ para os casos cuja infecção ocorreu nas últimas 12 semanas e alta avidez ( $>60 \%)$ para aqueles ocorridos há mais de 12 semanas ${ }^{1}$. O diagnóstico da infecção fetal pode ser realizado por meio da cordocentese, realizada até a $22^{\mathrm{a}}$ semana de gestação para detecção da resposta imune fetal (pesquisa de anticorpos IgM). Além deste, dispõese da amniocentese para realização da reação em cadeia da polimerase (PCR) no líquido amniótico, cuja sensibilidade atinge 97,4\%, bem como a ecografia, cuja sensibilidade é de $20 \%$. Constituem achados sugestivos de infecção fetal, pela ultrasonografia, a ventriculomegalia cerebral, microcefalia, calcificações intracranianas, hepatoesplenomegalia, ascite e placentomegalia ${ }^{1}$.

Objetivou-se com o presente estudo o conhecimento da freqüência da toxoplasmose aguda, sua taxa de TV e a evolução perinatal dos fetos infectados na nossa região. Objetivou-se, ainda, avaliar a relação entre os principais testes para diagnóstico da toxoplasmose durante a gestação, bem como a relação entre faixa etária e a infecção aguda pelo T. gondii.

\section{Pacientes e Métodos}

Estudo prospectivo longitudinal no qual foram incluídas 32.512 gestantes submetidas à triagem pré-natal no período de novembro de 2002 a outubro de 2003, em todo o estado de Mato Grosso do Sul (Brasil). Esta triagem é realizada pelo Programa de Proteção à Gestante de Mato Grosso do Sul (PPGMS), desde novembro de 2002, abrangendo todos os municípios e 95,3\% das mulheres grávidas do estado. O Programa inclui investigação sorológica de 10 infecções (HIV, hepatite B, hepatite C, HTLV, toxoplasmose, doença de Chagas, herpes simples, sífilis, citomegalovirus e rubéola) e a fenilcetonúria materna, por meio da técnica de papel filtro.

A gestante ao iniciar o acompanhamento médico pré-natal, recebe solicitação da coleta de gota de sangue digital para o papel filtro, que é enviado do posto de coleta até o laboratório do Instituto de Pesquisa, Ensino e Diagnóstico (IPED) da APAE de Campo Grande-MS, conveniado à Secretaria Estadual de Saúde, com apoio das Secretarias Municipais de Saúde do Estado de Mato Grosso do Sul. Deste laboratório os resultados são enviados para os respectivos centros de triagem, solici- tando nova coleta se os resultados forem indeterminados. Neste caso, a nova coleta, com amostra de soro, destina-se ao Laboratório Central (LACEN) da Fundação Serviços Estaduais de Saúde para contraprova.

A técnica consiste na coleta de sangue das pacientes, proveniente da polpa digital ou de punção venosa, com deposição no papel filtro em área previamente demarcada. Após secagem da amostra (até 4 horas), o papel filtro é enviado ao laboratório IPED-APAE em Campo Grande, não ultrapassando período superior a 24 horas após a coleta. Após chegada ao laboratório, a amostra de sangue é resuspendida, e então processada pelos testes sorológicos padrões para cada doença.

Especificamente para a infecção pelo $T$. gondi, o método sorológico utilizado na triagem foi ensaio imunoenzimático (ELISA), com sensibilidade de $99,4 \%$ e especificidade de $99,8 \%$, para pesquisa de anticorpos IgM, e sensibilidade de 99,3\% e especificidade de $99,8 \%$ para pesquisa de anticorpos IgG contra este parasita.

Para o estudo da prevalência da toxoplasmose aguda na gestação foram incluídas na amostra todas as gestantes que apresentaram sorologia para toxoplasmose aguda positiva (presença de anticorpos anti-Toxoplasma gondii IgM positivos), de qualquer faixa etária, atendidas em um serviço médico de pré-natal, entre novembro de 2002 e outubro de 2003. Em seguida ao resultado positivo para toxoplasmose aguda foi realizado o teste de avidez dos anticorpos IgG, para confirmação da época da infecção, oferecido também pelo PPG-MS. Aquelas cuja avidez foi baixa $(<30 \%)$, e que se encontravam em acompanhamento no ambulatório de gestação de alto risco da Universidade Federal de Mato Grosso do Sul, foram submetidas à amniocentese para coleta de líquido amniótico e realização da PCR, método Multiplex, no laboratório Fleury em São Paulo, para confirmação da infecção fetal.

Posteriormente ao nascimento do feto, foi solicitada a sorologia para toxoplasmose pelo método ELISA, estando contida no teste de triagem neonatal realizado pelo laboratório do IPED-APAE. O seguimento dos recém-nascidos ocorreu nos respectivos centros de origem, com a realização de exames complementares para as crianças cuja sorologia pudesse sugerir infecção congênita: fundoscopia ocular, teste audiométrico, ultrasonografia de fontanelas e tomografia computadorizada de crânio. Foram incluídas como casos de infecção congênita aquelas nas quais foi detectada a presença de IgM anti-Toxoplasma gondii no sangue dos neonatos assintomáticos ou portadores de sinais clínicos e de imagem sugestivos des- 
ta infecção e aqueles casos em que a PCR prénatal demonstrou infecção fetal.

As informações foram obtidas nos centros de atendimento médico destas pacientes (municipais, estaduais e federais), por meio de pesquisa em prontuários, contato telefônico direto com a maioria das gestantes e visita domiciliar quando necessário. Houve consentimento de todas as pacientes participantes do estudo para que tais informações fossem utilizadas. O estudo foi aprovado pela Comissão de Ética em Pesquisa da Universidade Federal do Mato Grosso do Sul.

A avaliação das variáveis foi feita pelas médias, ao passo que a correlação entre algumas variáveis foi avaliada pelo teste do $\chi^{2}$ e teste de Fisher bicaudado em tabelas de contingência de dupla entrada. Foi aceito $\mathrm{p}<0,05$ como critério para rejeição das hipóteses de nulidade. Considerou-se nula a hipótese de não haver associação entre a idade materna e infecção aguda pelo $T$. gondii. Também foi considerada nula a hipótese de não haver associação entre os resultados do teste de avidez de anticorpos IgG e a presença de infecção fetal.

\section{Resultados}

Foram encontrados 137 casos de toxoplasmose com sorologia IgM positiva durante a gravidez dentre um contingente de 32.512 pacientes triadas no período de novembro de 2002 a outubro de 2003. Este valor resulta em freqüência de 0,42\% para a infecção aguda pelo T. gondii (42 casos em 10.000 pacientes) na população de gestantes do estado de Mato Grosso do Sul. Observou-se que 91,6\% das gestantes apresentaram sorologia IgG reagente e IgM não reagente, demonstrando exposição prévia à infecção, e que $8 \%$ apresentaram sorologia IgG e IgM não reagentes, revelando-se suscetíveis a adquirir a infecção.

Nas gestantes com sorologia IgM reagente, a faixa etária variou de 14 a 39 anos, com média de $23 \pm 5,9$ anos. Observou-se predomínio de gestantes com idade entre 20 e 24 anos (32,1\%), sendo que não houve nenhum caso de toxoplasmose em gestantes com idade superior a 40 anos. Não houve relação significativa estatisticamente entre faixa etária e infecção materna aguda pelo $T$. gondii, conforme dados expostos na Tabela 1 $\left(\mathrm{p}=0,73 ; \chi^{2}=1,288\right)$.

Com referência à aderência ao programa prénatal, em média o diagnóstico da infecção materna foi realizado com $15,6 \pm 7,3$ semanas, variando entre 4 e 36 semanas, sendo predominante o diagnóstico no segundo trimestre de gestação, com
$45,8 \%$, seguido do primeiro trimestre com $35,4 \%$. O número médio de consultas pré-natais realizadas foi de $7,7 \pm 2,9$; o número médio de ultrasonografias realizadas foi de $3,0 \pm 1,5$ exames.

Tabela 1 - Relação entre a idade das pacientes e a sorologia IgM para toxoplasmose.

\begin{tabular}{lccc}
\hline Idade & $\begin{array}{c}\text { Sorologia } \\
\text { IgM positiva } \\
\mathbf{n}\end{array}$ & $\begin{array}{c}\text { Sorologia } \\
\text { IgM negativa }\end{array}$ & $\begin{array}{c}\text { Total } \\
\mathbf{n}\end{array}$ \\
\hline$\leq 14$ anos & $4(0,01 \%)$ & $804(2,5 \%)$ & $808(2,5 \%)$ \\
$15-19$ anos & $39(0,12 \%)$ & $9.059(28,3 \%)$ & $9.098(28,4 \%)$ \\
$20-29$ anos & $78(0,24 \%)$ & $17.245(53,8 \%)$ & $17.319(54,1 \%)$ \\
$30-40$ anos & $16(0,05 \%)$ & $4.779(14,9 \%)$ & $4.793(15 \%)$ \\
Total & $137(0,42 \%)$ & $31.887(99,5 \%)$ & $32.024(100 \%)$ \\
\hline$\chi^{2}=1,288 ; p=0,73$. & & &
\end{tabular}

O teste da avidez dos anticorpos IgG antitoxoplasma realizado em 126 gestantes (92\% da amostra) para diferenciar os casos agudos dos crônicos foi processado em média com 15,6 semanas de gestação, sendo 50,5\% durante o primeiro trimestre gestacional, 35,6\% durante o segundo trimestre e $13,9 \%$ realizados durante o último trimestre. Os resultados encontrados estão expressos na Tabela 2. Houve relação significativa $(p=0,001)$ entre o teste de avidez baixo $(<30 \%)$ e presença de infecção fetal, bem como ausência de toxoplasmose fetal quando a avidez apresenta-se elevada (>60\%) (Tabela 3 ).

Tabela 2 - Resultados do teste de avidez dos anticorpos IgG anti-Toxoplasma gondii em pacientes com IgM reagente.

\begin{tabular}{lcc}
\hline Avidez & $\mathbf{n}$ & $\%$ \\
\hline$>60 \%$ & 77 & 61,1 \\
$30-60 \%$ & 38 & 30,2 \\
$<30 \%$ & 11 & 8,7 \\
Total & 126 & 100 \\
\hline
\end{tabular}

Tabela 3 - Associação entre os testes de avidez dos anticorpos IgG para toxoplasmose realizados no primeiro trimestre gestacional e a infecção fetal.

\begin{tabular}{lccc}
\hline \multirow{2}{*}{ Avidez } & \multicolumn{2}{c}{ Infecção fetal } & Total \\
& Presente & Ausente & \\
\hline Baixa $(<30 \%)$ & $3(5 \%)$ & $6(9 \%)$ & $9(14 \%)$ \\
Elevada $(>60 \%)$ & $0(0 \%)$ & $57(86 \%)$ & $57(86 \%)$ \\
Total & $3(5 \%)$ & $63(95 \%)$ & $66(100 \%)$ \\
\hline Teste exato de Fisher: $\mathrm{p}=0,0018$. & &
\end{tabular}


Um total de 45 pacientes $(32,8 \%)$ foi encaminhado para amniocentese e realização da PCR do líquido amniótico, com finalidade de diagnóstico da infecção fetal. O resultado do teste diagnóstico demonstrou-se negativo em 43 gestantes $(95,5 \%)$ e positivo em dois casos $(4,5 \%)$. Dentre os resultados de PCR negativas não houve caso de infecção após o acompanhamento neonatal. Com relação aos dois casos PCR positivos, a infecção neonatal foi confirmada pela sorologia e métodos de imagem. Com isso, no presente estudo, a PCR em líquido amniótico mostrou sensibilidade e especificidade de $100 \%$. Também foi possivel verificar associação significativa estatisticamente $(p=0,001)$ entre infecção fetal (PCR em líquido amniótico) e infecção neonatal confirmada.

Das 137 gestantes do estudo, pôde-se obter o resultado neonatal de 111 (81\%) recém-natos. Destes, foram 104 nascidos vivos, 3 (2,7\%) aborta- mentos, dois $(1,8 \%)$ natimortos de causa não esclarecida e dois $(1,8 \%)$ óbitos neonatais. Malformações congênitas foram encontradas em dois $(1,9 \%)$ nascidos vivos.

Houve infecção congênita em quatro casos, resultando em taxa de TV de 3,9\%. Dos recémnascidos com toxoplasmose congênita, um deles apresentou malformações neurológicas graves diagnosticadas pela ultra-sonografia no pré-natal. A investigação com PCR indicou a infecção fetal e ocorreu óbito após o nascimento, aos nove meses de idade. Outro feto evoluiu com óbito intra-útero, sendo portador de graves malformações encefálicas. A PCR no pré-natal também havia demonstrado ocorrência de infecção fetal. Os dois casos restantes foram nascidos vivos assintomáticos nos quais a sorologia IgM anti-Toxoplasma gondii demonstrou positividade após o nascimento (Tabela 4).

Tabela 4 - Descrição dos casos de infecção congênita ocorridos no estudo.

\begin{tabular}{|c|c|c|c|}
\hline $\begin{array}{l}\text { Casos de infecção } \\
\text { congênita }\end{array}$ & $\begin{array}{l}\text { Avidez } \\
\text { (época da realização) }\end{array}$ & PCR & $\begin{array}{l}\text { Alterações observadas } \\
\text { nos exames complementares }\end{array}$ \\
\hline 1 & $\begin{array}{l}27 \% \\
\text { (18 semanas) }\end{array}$ & Positiva & $\begin{array}{l}\text { Hidrocefalia fetal, parto pré-termo e natimorto. Alterações placentárias } \\
\text { e do SNC compatíveis com toxoplasmose. }\end{array}$ \\
\hline 2 & $\begin{array}{c}28,8 \% \\
\text { (36 semanas) }\end{array}$ & Não fez & Calcificações cerebrais peritalâmicas \\
\hline 4 & $\begin{array}{c}33,8 \% \\
\text { (12 semanas) }\end{array}$ & Positiva & Malformação encefálica grave, hidrocefalia; óbito aos nove meses \\
\hline
\end{tabular}

\section{Discussão}

Encontramos uma freqüência da infecção recente pelo T. gondii de $0,42 \%$ no estado de Mato Grosso do Sul, sendo que esta taxa é menor que no Rio de Janeiro $(1,4 \%)^{4}$, em Pernambuco $(2,4 \%)^{5}$, Bahia $(1,19 \%)^{7}$, Paraná $(1,8 \%)^{8}$ e Rio Grande do Sul $\left(0,6 \%{ }^{12} ; 2,4 \%^{13}\right)$. No entanto, comparando-se dados da literatura internacional, podem-se encontrar resultados semelhantes na Noruega $(0,17 \%)^{14}$, Nova Zelândia $(2,4 \%)^{15}$, Suécia $(0,05 \%)^{16}$, Malásia $(4 \%)^{17}$, China $(3,38 \%)^{18}$ e Nigéria $(1,8 \%)^{19}$. Essas variações podem ser explicadas uma vez que a prevalência da soropositividade entre gestantes oscila de acordo com a região geográfica, características climáticas e hábitos nutricionais ${ }^{13}$. O caráter amplo e descentralizado da amostra populacional aqui estudada também contribui para a dife- rença encontrada, pois a maioria dos estudos citados foram realizados em centros de referência, inclusive alguns especializados em gestação de alto risco, sendo a amostragem do presente estudo correspondente às gestantes de todo o estado.

Ressalta-se, ainda, a elevada exposição prévia das gestantes sul-matogrossenses à infecção pelo $T$. gondii $(91,4 \%)$, uma vez que em outros estados, como Rio de Janeiro $(77,1 \%)^{4}$, Pernambuco $(69,4 \%)^{5}$, Rio Grande do Sul $\left(59,8 \%{ }^{13} ; 74,5 \%{ }^{6}\right)$, Bahia $(64,9 \%)^{7}$, Paraná $(67 \%)^{8}$, e Mato Grosso $(70,7 \%)^{20}$, o grau de exposição é menor. A elevada exposição prévia e a baixa suscetibilidade $(8 \%)$ da população à infecção pelo $T$. gondi, são fatores que podem estar relacionados à menor freqüência da infecção na amostra estudada.

Ao se analisarem as variáveis epidemiológicas do presente estudo, verifica-se que houve predomínio de gestantes jovens e primigestas, 
sendo a média de idade de 23 anos. Em estudo de Varella et al. ${ }^{13}$, a idade das mulheres soropositivas variou entre 13 e 45 anos, encontrando uma média de 26,3 anos. Há evidências de que a soropositividade para toxoplasmose (presença de anticorpos IgG) aumenta em proporção direta com a idade das gestantes, e a presença destes confere fator protetor, afastando o risco de TV. Deve-se esperar exatamente que a primo-infecção, e conseqüentemente a toxoplasmose aguda, ocorra em faixas etárias mais jovens ${ }^{3,13}$. Na presente amostra, não houve associação significativa entre faixa etária e presença de infecção aguda materna.

Com relação aos métodos para realização do diagnóstico materno, foi utilizada a pesquisa de anticorpos IgM como método de rastreamento e o teste da avidez dos anticorpos IgG, como método elucidatório da época da infecção adquirida. A avidez de IgG demonstra grande valor na diferenciação de infecção crônica (ocorrida há mais de 12 semanas), na qual apresenta-se elevada (>60\%), da infecção recente (ocorrida há menos de 12 semanas), cuja avidez apresenta-se baixa $(<30 \%)^{3,21}$. No entanto sabe-se que valores baixos de avidez de IgG podem permanecer por mais de um ano, não indicando necessariamente infecção recente ${ }^{21,22}$. Aproximadamente $40 \%$ das pacientes IgM ELISA negativas apresentam avidez baixa ou intermediária ${ }^{21}$, e muitas gestantes com IgM ELISA positivas apresentam resultados inconclusivos ${ }^{22}$, fato que ocorreu em 30,2\% das pacientes aqui estudadas. Desse modo, a principal utilidade do teste de avidez dos anticorpos IgG se concentra no primeiro trimestre da gestação ${ }^{21}$, no qual valores elevados de avidez podem indicar que a infecção primária ocorrera em período anterior à gestação, existindo risco reduzido para o feto, não havendo, nesses casos, necessidade de tratamento 22,23 . Dentre as pacientes estudadas que obtiveram avidez elevada no primeiro trimestre de gestação não houve TV. Quando a avidez foi baixa $(<30 \%)$ houve relação significativa com a presença de infecção fetal.

Das quatro pacientes cujos recém-natos apresentaram a toxoplasmose congênita confirmada, a avidez de IgG foi baixa em três delas (Tabela 4). Ressalta-se que tais pacientes apresentaram os valores baixos de avidez de IgG com 18, 23 e 36 semanas de gestação, fato que confirmou a ocorrência de infecção nas últimas 12 semanas, portanto dentro do curso gestacional. Nos casos de toxoplasmose congênita mais grave, em que houve o óbito fetal e malformação encefálica extensa, o momento da infecção ocorreu no primeiro trimestre. No caso de toxoplasmose congênita mais branda, o recém-nato encontrava-se assintomático, entretanto foram observadas calcificações no parênquima cerebral localizadas em regiões periventriculares. Neste caso o momento da infecção possivelmente ocorreu no terceiro trimestre de gestação (Tabela 4).

A confirmação da infecção fetal foi realizada pela PCR do líquido amniótico, sendo o método diagnóstico de escolha cuja sensibilidade atinge $97,4 \%{ }^{3}$. Em estudo desenvolvido por Romand et al. ${ }^{24}$, encontraram-se sensibilidade de $64 \%$, valor preditivo negativo de $87,8 \%$, especificidade e valor preditivo positivo de $100 \%$ para a PCR no líquido amniótico. Quando avaliou-se a PCR no líquido amniótico entre 45 pacientes, encontraram-se sensibilidade e especificidade de $100 \%$ no presente estudo. No entanto, como demonstram estudos mais acurados, a sensibilidade é relativamente menor que a especificidade e o valor preditivo positivo, variando significativamente de acordo com a idade gestacional em que a infecção foi adquiri$\mathrm{da}^{24}$. A sensibilidade é mais elevada quando realizada entre 17 e 21 semanas de gestação, permanecendo próxima aos $65 \%{ }^{24}$. Desse modo, pesquisa negativa de infecção fetal pela PCR afasta a ocorrência de infecção congênita na maioria dos $\operatorname{casos}^{24}$. Observou-se na atual casuística relação significativa entre a positividade intra-útero da PCR com a infecção neonatal confirmada.

A TV da toxoplasmose ocorre em torno de metade das pacientes não tratadas, podendo variar de 20 a $70 \%{ }^{3}$, sendo o tratamento capaz de reduzir os riscos de infecção congênita em 50\% $\%^{1,3}$. Dados da literatura indicam que o diagnóstico e tratamento precoce durante a gestação evitam e minimizam as lesões no neonato ${ }^{6}$. Por isso é fundamental o esclarecimento das gestantes quanto à necessidade do tratamento e sua eficácia.

Na presente casuística, a taxa de TV encontrada foi de $3,9 \%$. As taxas de transmissão, no entanto, oscilam conforme o trimestre gestacional, variando de $15 \%$ no primeiro trimestre a $60 \%$ no terceiro trimestre ${ }^{6}$. Em estudos desenvolvidos no exterior são descritas taxas de TV variáveis: na China, $8,2 \%^{18}$, e na Áustria, $19,4 \%^{25}$. Na Norue$\mathrm{ga}^{14}$ as taxas variaram de acordo com o trimestre gestacional sendo de $13 \%$ no primeiro, $29 \%$ no segundo e 50\% no terceiro trimestre gestacional. Em estudo nacional semelhante a taxa de TV da toxoplasmose encontrada foi de $6 \%{ }^{6}$. A taxa de TV encontrada no presente trabalho está de acordo com estudo realizado em gestantes tratadas (7\%), variando de 1,2 a $28,9 \%$, de acordo com a fase da gestação em que ocorreu a infecção ${ }^{26}$. Dentre os fatores relacionados com a freqüência da primoinfecção na gestação estão a prevalência da infecção na comunidade e a freqüência dos contactantes infectados, ambos fatores altamen- 
te presentes na população aqui estudada. Como a maioria da gestantes do presente estudo são IgG positivas, o reduzido número de gestantes suscetíveis apresenta alto risco de adquirir a infecção na gravidez.

Conforme os objetivos do estudo, os dados expostos permitem descrever a situação atual da toxoplasmose em gestantes sul-matogrossenses. A freqüência da infecção aguda esteve abaixo dos parâmetros nacionais, sendo que $91,6 \%$ da população estudada já entrou em contato prévio com o T. gondii e desenvolveu imunidade contra o parasita. Contudo, apesar desta elevada exposição prévia e do baixo número de gestantes suscetíveis à toxoplasmose (8\%) no estado de Mato Grosso do Sul, a taxa de TV não discordou do encontrado em outros estudos, demonstrando a importância do tratamento a ser instituído, permitindo afirmar que uma baixa suscetibilidade da população de gestantes não determina uma maior proteção em relação à passagem transplacentária do parasita. Além disso, é importante salientar que o teste de avidez dos anticorpos IgG é útil para orientar a terapêutica e avaliar o risco de TV, quando associado à idade gestacional e à data da realização do exame, e permitindo, inclusive, afastar totalmente o risco de TV quando há avidez elevada previamente a 12 semanas de gestação.

Desse modo recomenda-se, em face de gestantes com resultado IgM reagente para toxoplasmose com idade gestacional inferior a 12 semanas, a realização na mesma amostra do teste de avidez para IgG. Caso o resultado seja de avidez elevada (>60\%), torna-se desnecessária a pesquisa ativa de infecção fetal, bem como a instituição do tratamento materno.

\section{Referências}

1. Santana RM, Andrade FM, Moron AF. Infecções TORCH e gravidez. In: Prado FC, Ramos J, Ribeiro do Valle J, editores. Atualização terapêutica. 21a ed. São Paulo: Artes Médicas; 2003. p. 1111-2.

2. Frenckel JK. Toxoplasmose. In: Veronesi R, editor. Tratado de infectologia. 2a ed. São Paulo: Atheneu; 2002. p. 1310-25.

3. Moron AF, Carvalho FHC, Santana RM. Toxoplasmose. In: Schor N, editor. Guia de obstetrícia. São Paulo: Manole; 2003. p. 485-9.

4. Meirelles Filho J. Toxoplasmose e gravidez: inquérito sorológico em gestantes e seus recém-nascidos na Maternidade-Escola da Universidade Federal do Rio de Janeiro. J Bras Ginecol. 1985;95(9):393-401.
5. Nóbrega MC, Magalhães V, Albuquerque Y, Magalhães C, Arcoverde C. Toxoplasmose em gestantes e em seus recém-nascidos, atendidos no Hospital das Clínicas da Universidade Federal de Pernambuco. RBM Cad Ginecol Obstet. 1999;56:23-9.

6. Spalding SM, Amendoeira MRR, Ribeiro LC, Silveira C, Garcia AP, Camillo-Coura Léa. Estudo prospectivo de gestantes e seus bebês com risco de transmissão de toxoplasmose congênita em município do Rio Grande do Sul. Rev Soc Bras Med Trop. 2003;36(4):483-91.

7. Nascimento ILO, Carvalho S, Asfora S, Freire SM, Simões JM, Schaer R, et al. Estudo da prevalência de anticorpos anti-Toxoplasma gondii em mulheres grávidas no Estado da Bahia. Rev Cienc Med Biol. 2002;1(1):12-5.

8. Reiche EMV, Morimoto HK, Farias GN, Hisatsugu KR, Geller L, Gomes ACL, et al. Prevalence of American trypanosomiasis, syphilis, toxoplasmosis, rubella, hepatitis $\mathrm{B}$, hepatitis $\mathrm{C}$, human immunodeficiency virus infection, assayed through serological tests among pregnant patients, from 1996 to 1998, at the Regional University Hospital Norte do Paraná. Rev Soc Bras Med Trop. 2000;33(6):519-27.

9. Kasper LH. Infecção por toxoplasma. In: Braunwald E, Fauci AS, Kasper DL, Hauser SL, Longo DL, Jameson JL, editors. Harrison medicina interna. 15a ed. Rio de Janeiro: McGraw-Hill; 2002. p. 1294-8.

10. Freij BJ, Sever JL. Toxoplasmosis. Pediatr Rev. 1991;12(8):227-36.

11.Hennequin C, Dureau P, N'Guyen N, Thulliez P, Gagelin B, Dufier JL. Congenital toxoplasmosis acquired from an immune woman. Pediatr Infect Dis J. 1997;16(1):75-7.

12. Mozzato L, Procianoy RS. Incidence of congenital toxoplasmosis in southern Brazil: a prospective study. Rev Inst Med Trop São Paulo. 2003;45(3):147-51.

13. Varella IS, Wagner MB, Darela AC, Nunes LM, Müller RW. Seroprevalence of toxoplasmosis in pregnant women. J Pediatr (Rio J). 2003;79(1):69-74.

14. Jenum PA, Stray-Pedersen B, Melby KK, Kapperud G, Whitelaw A, Eskild A, et al. Incidence of Toxoplasma gondii infection in 35,940 pregnant women in Norway and pregnancy outcome for infected women. J Clin Microbiol. 1998;36(10):2900-6.

15. Morris A, Croxson M. Serological evidence of Toxoplasma gondii infection among pregnant women in Auckland. N Z Med J. 2004; 117(1189):U770.

16. Evengard B, Petersson K, Engmar ML, Wiklund S, Ivarsson SA, Tear-Fahnehjelm K, et al. Low incidence of toxoplasma infection during pregnancy and in newborns in Sweden. Epidemiol Infect. 2001;127(1):121-7. 
17. Nissapatorn V, Noor Azmi MA, Cho SM, Fong MY, Init I, Rohela M, et al. Toxoplasmosis: prevalence and risk factors. J Obstet Gynaecol. 2003;23(6):618-24.

18. Zhang AM, Zhang T, Hao ZY. A seroepidemic survey on the infection of toxoplasma in pregnant women and its significance to better child-bearing. Zhonghua Liu Xing Bing Xue Za Zhi. 1996;17(5):278-80.

19. Olusi T, Gross U, Ajayi J. High incidence of toxoplasmosis during pregnancy in Nigeria. Scand J Infect Dis. 1996;28(6):645-6.

20.Leão PRD, Meirelles Filho J, Medeiros SF. Toxoplasmose: soroprevalência em puérperas atendidas pelo Sistema Único de Saúde. Rev Bras Ginecol Obstet. 2004;26(8):627-32.

21. Montoya JG, Liesenfeld O, Kinney S, Press C, Remington JS. VIDAS test for avidity of Toxoplasmaspecific immunoglobulin $\mathrm{G}$ for confirmatory testing of pregnant women. J Clin Microbiol. 2002;40(7):2504-8.
22. Remington JS, Thulliez P, Montoya JG. Recent developments for diagnosis of toxoplasmosis. J Clin Microbiol. 2004;42(3):941-5.

23. Lappalainen M, Hedman K. Serodiagnosis of toxoplasmosis. The impact of measurement of IgG avidity. Ann Ist Super Sanità. 2004;40(1):81-8.

24. Romand S, Wallon M, Franck J, Thulliez P, Peyron F, Dumon H. Prenatal diagnosis using polymerase chain reaction on amniotic fluid for congenital toxoplasmosis. Obstet Gynecol. 2001;97(2):296-300.

25.Lebech M, Andersen O, Christensen NC, Hertel J, Nielsen HE, Peitersen B, et al. Feasibility of neonatal screening for toxoplasma infection in the absence of prenatal treatment. Lancet 1999;353(9167):1834-7.

26. Mirlesse V, Jacquemard F, Daffos F. Toxoplasmose au cours de la grossesse: diagnostic et nouvelles possibilités thérapeutiques. Presse Med. 1993;22(6):258-62. 